Florence Smits, 2003, La France, un territoire de l'Union Européenne

Paris, Hatier, collection initial, 250 p.

\title{
Simon Edelblutte
}

\section{OpenEdition}

\section{Journals}

Édition électronique

URL : http://journals.openedition.org/rge/2333

DOI : $10.4000 /$ rge.2333

ISSN : 2108-6478

Éditeur

Association des géographes de l'Est

Édition imprimée

Date de publication : 1 septembre 2003

ISSN : 0035-3213

\section{Référence électronique}

Simon Edelblutte, «Florence Smits, 2003, La France, un territoire de I'Union Européenne », Revue

Géographique de l'Est [En ligne], vol. 43 / 4 | 2003, mis en ligne le 24 novembre 2010, consulté le 22 septembre 2020. URL : http://journals.openedition.org/rge/2333 ; DOI : https://doi.org/10.4000/rge. 2333

Ce document a été généré automatiquement le 22 septembre 2020

Tous droits réservés 


\title{
Florence Smits, 2003, La France, un territoire de l'Union Européenne
}

Paris, Hatier, collection initial, 250 p.

\author{
Simon Edelblutte
}

\section{RÉFÉRENCE}

Florence Smits, 2003, La France, un territoire de l'Union Européenne, Paris, Hatier, collection initial, $250 \mathrm{p}$.

1 Paru à la fin de 2003, cet ouvrage de 250 pages fait partie de la collection « initial » de l'éditeur Hatier qui y propose déjà, dans notre discipline, un dictionnaire plusieurs fois réédité et fort utile aux étudiants comme le sera sans doute celui-ci.

2 Servi par un style rigoureux et surtout par un véritable talent de l'auteur pour le tri, le classement, la hiérarchisation des idées, ce livre est donc une géographie de la France. Une de plus dans une catégorie déjà bien remplie? Pas seulement, car si cet ouvrage a certes pour premier mérite - partagé par ceux de sa catégorie - d'actualiser la vision géographique du territoire national, il se distingue à plusieurs titres en proposant « une nouvelle lecture du territoire français» (p. 7), ainsi que le précise A. Ciattoni dans sa préface.

3 Cette originalité tient d'abord au plan choisi par F. Smits. Délaissant le plan classique, elle aborde en effet son sujet par un gros chapitre sur l'économie (ch. 1), puis continue sur la métropolisation du territoire (ch. 2) autour de villes regroupant aujourd'hui, par le jeu des unités et des aires urbaines, $74 \%$ de la population française et surtout commandant et organisant l'espace national. Les chapitres suivants sont consacrés à l'aménagement (ch. 3), aux milieux et aux risques (ch. 4), à la population (ch. 5), pour terminer par un court chapitre - qui s'apparente plus à une conclusion - sur la place de la France dans le monde (ch. 6).

4 Les deux premiers chapitres, sur lesquels l'auteur base l'essentiel du travail, représentent néanmoins plus de la moitié de l'ouvrage et on peut regretter un certain 
déséquilibre aux dépens de questions abordées plus rapidement et dont certaines auraient mérité, au regard de l'actualité et des préoccupations actuelles des géographes, d'être plus développées (risques, rôle international de la France...).

5 L'autre originalité de l'ouvrage tient dans la volonté d'inscrire (ainsi que le précise le titre) la France dans l'ensemble plus vaste qu'est l'Union Européenne (UE), évidemment incontournable pour expliquer les dynamiques spatiales actuelles du territoire national. Si ce pari est largement tenu, notamment par la présentation de nombreux tableaux et cartes comparant ou intégrant la France dans l'UE, il existe cependant quelques chapitres (ch. 2, ch. 4) où le texte sur la France est rattaché, un peu artificiellement par de longs titres de parties, à L'UE.

Complétant cette approche novatrice, un des points forts de l'ouvrage est l'insertion de nombreux tableaux statistiques, graphiques et cartes diverses soulignant certains aspects du texte. Certaines, comme la figure de la p. 110 définissant les notions d'unités urbaines, de pôles urbains ou encore d'aires urbaines clarifient des notions souvent confondues par les étudiants et leur seront donc fort utiles. Malheureusement, et c'est peut-être le seul vrai défaut de cet ouvrage, les différentes documents ne sont ni numérotés, ni appelés dans le texte, ce qui ne facilite pas la lecture de l'ouvrage. Enfin, on peut regretter que certaines cartes complexes (p. 171, p. 177) voient leur lisibilité largement réduite par le choix éditorial du noir et blanc ( 6 catégories de grisés...).

7 Complété par une bibliographie utile (car bien ciblée sur l'essentiel), classée par chapitres et intégrant quelques adresses internet incontournables pour l'acquisition de données actualisées, cet ouvrage à la fois concis et original se distingue positivement dans une production assez abondante sur la géographie de la France.

\section{AUTEURS}

\section{SIMON EDELBLUTTE}

Université de Nancy 2 